\title{
Features of effective primary health care models in rural and remote Australia: a case-study analysis
}

\author{
John Wakerman, John S Humphreys, Robert Wells, Pim Kuipers, Judith A Jones, Philip Entwistle and Leigh Kinsman
}

A

third of Australia's population lives outside major cities. ${ }^{1}$ Many residents of the 1500 rural and remote communities with fewer than 5000 inhabitants face significant health disadvantage and reduced access to health services. ${ }^{1}$ Despite a raft of specific rural health policies since the mid 1990s, ${ }^{2}$ the "inverse care law" still applies (ie, the availability of good health care tends to vary inversely with the need of the population served). ${ }^{3}$ In a wealthy country such as Australia, this inequity is unacceptable. However, empirical evidence to account for the failure of implementation of rural health policy, ${ }^{4}$ the lack of sustainability of rural primary health care (PHC) services, ${ }^{5}$ and the failure to generalise successful programs $s^{6,7}$ is lacking.

Our previous research described innovative models of comprehensive PHC (as defined by the World Health Organization ${ }^{8}$ ) in rural and remote Australia, a model typology, conceptual framework and resultant policy implications. ${ }^{6,9,10}$ This follow-up study describes the factors and processes that facilitate or inhibit implementation, sustainability and generalisation of effective models of PHC service delivery in rural and remote Australia - issues about which little has been published to date.

\section{METHODS}

Based on results of our previous systematic review, ${ }^{10}$ six identifiably sustainable PHC services were selected for detailed casestudy analysis. The services were purposively selected to reflect a diverse range of rural and remote settings, PHC models, focus areas (health promotion, disease prevention, rehabilitation and clinical services) and national priorities (medical workforce supply, mental health and chronic disease care), as well as the multidisciplinary nature of PHC. Each service had been previously independently evaluated. ${ }^{11-16}$

The services were:

- North West Queensland Allied Health Service (NWQAHS) hub and spoke model ${ }^{11}$

- Griffith Area Palliative Care Service (GAPS) integrated service model; ${ }^{12}$

- Katherine West Health Board (KWHB) comprehensive PHC model; ${ }^{13}$

\section{ABSTRACT}

Objective: To describe the factors and processes that facilitate or inhibit implementation, sustainability and generalisation of effective models of primary health care (PHC) service delivery in rural and remote Australia.

Design: Case-study approach, including review of relevant literature, interviews with key informants, site visits and direct observation. Thematic analysis and template analysis were used with interview transcripts. An expert reference group provided feedback and advice on policy relevance.

Setting and participants: Six PHC services in small communities across rural and remote Australia were selected based on results of a previous systematic review; they reflected diverse rural and remote settings and PHC models, and the multidisciplinary nature of PHC. Sites were visited, and 55 individuals associated with the establishment and operation of these services were interviewed between July 2006 and December 2007.

Results: Independent and template analysis confirmed the usefulness of a conceptual framework, which identified three key "environmental enablers" - supportive policy; federal and state/territory relations; and community readiness - and five essential service requirements - governance, management and leadership; funding; linkages; infrastructure; and workforce supply. Systematically addressing each of these factors improves effectiveness and lessens the threat to service sustainability.

Conclusions: Evidence from existing effective rural and remote PHC services can inform the health care reform agenda, in Australia and other countries. The evidence highlights the need for improved governance, management and community involvement, as well as strong, visionary political leadership to achieve a more responsive and better coordinated health system which could help eliminate existing health status differentials between cities and rural areas. In Australia, establishment of a single national health system, operationalised at a regional level, would obviate much of the current inefficiency and poor coordination.

MJA 2009; 191: 88-91

- Rural and Remote Medical Services (RARMS) discrete model; ${ }^{14}$

- Mallee Track Health and Community Service (MTHCS) integrated service model; ${ }^{15}$ and

- North East Tasmania Primary Mental Health Care (NETPMHC) integrated service model. $^{16}$

Between July 2006 and December 2007, we conducted in-depth interviews with key informants identified as having a significant role in the implementation or operation of each service by previous research, ${ }^{9}$ reference group members or snowballing. Those interviewed included:

- funders;

- state or federal health authorities;

- auspicing bodies;

- general practitioners, nurses, allied health professionals, practice managers and other service delivery staff;
- consumers; and

- Divisions of General Practice and other professional groups.

Different combinations of two researchers visited each site, enabling direct observation of service facilities and informal interaction with staff. A national reference group provided feedback and guidance on the policy significance of findings.

Semistructured interviews were recorded and transcribed. Two interviewers documented summary themes and issues based on the recorded interviews and detailed notes. Using our previous framework ${ }^{10}$ as a template or coding frame, ${ }^{17}$ we identified and synthesised common themes. To validate the process and identify themes that fell outside the template, transcripts were independently thematically coded ${ }^{18}$ by a team member not involved in the interviews, and analysed for emergent themes using NVivo 
software (QSR International, Cambridge, Mass, USA).

Ethics approval was granted by the Monash University and Northern Territory Top End Human Research Ethics Committees.

\section{RESULTS}

Fifty-five individuals were interviewed. Although interviews covered diverse issues, clearly consistent themes emerged in the initial post-interview analysis and subsequent independent coding and analysis. We identified three key "environmental enablers" - supportive policy; federal and state/territory relations; and community readiness - and five essential service requirements - governance, management and leadership; funding; linkages; infrastructure; and workforce supply.

\section{Environmental enablers}

\section{Supportive policy}

In the recent national policy context, senior policy officers suggested that many rural health initiatives had resulted from a "liberation of ideas" within government in response to concerns from disaffected rural and remote electorates. In 2000, health formed a "budget centrepiece for rural and remote Australia" because supporting health and social data existed, funds could "flow and generate impact quickly", and voters regularly interacted with health providers, such as doctors and pharmacists.

The policy context appeared to set the parameters for sustainability and generalisation of successful models. These were either supported by a policy (eg, KWHB, which was supported by the Coordinated Care Trial program) or a politically opportune source of funding (eg, NETPMHC, which was in the swinging seat of Bass in the leadup to a federal election). A senior public servant described a three-tiered policy and funding hierarchy, comprising "mainstream programs", such as the Medicare Benefits Scheme (MBS); "equalisation programs" for the bush, such as the Regional Health Services program and the Royal Flying Doctor Service; and "ad-hoc grants", which cause sustainability problems for both grantees and granters. He considered that reliance on pilot projects worked against sustainability and commented that "pilotitis causes us indigestion".

For effective models to be generalised to other contexts, there needs to be a political benefit for the government of the day. A number of service providers commented that, regrettably, high staff turnover and loss of corporate memory within the federal health department weaken the policy foundation from which to generalise successful pilot projects.

\section{Federal and state/territory relations}

An important barrier to health service implementation was perceived mistrust between federal and state/territory health authorities, and associated cost-shifting, lack of change management capability, and turf issues for state health authorities.

Public service views about federal-state relations varied. A state bureaucrat commented that generally the Commonwealth and the states were each "getting on with business". In contrast, a federal bureaucrat said, "We're wading in because the states aren't doing their fair share". Our interviews reflected considerable negotiation and cooperation in some cases (such as the establishment of coordinated care trials), and an increased understanding between the Australian Government and the jurisdictions as a result of rural health programs. The Multi Purpose Services (MPS) program is a good example of cooperation, according to a federal public servant, as it is straightforward to define an area's entitlement using an aged care formula, and then to pool acute care services funding.

In contrast, instances where federal versus state responsibilities for PHC were unclear, such as the provision of allied health services, had an adverse impact on generalising the models. In the words of one bureaucrat: "Information is power"; but information was not always provided in a manner that was timely or transparent.

\section{Community readiness}

Community involvement was seen as essential for effective service implementation and sustainability. Interviewees indicated that "influential families" exerting political pressure, and health professional and consumer activism were important in establishing these services. In relation to sustainability, a senior KWHB professional described the 2 -year process of community engagement as "deep consultation", which laid the "foundations" that ensured a community understanding of the risk involved, gained consent, established an effective governance structure, and allowed negotiation of financing arrangements. Ongoing accountability to the community also contributed to sustainability. In one service, high community expectations for a continuing service and the political consequences of not maintaining existing services were important drivers contributing to sustainability.

Several service models (NWQAHS, GAPS, KWHB and RARMS) have been adapted to, or informed, service development elsewhere. Models must relate to the local context: "Every community needs to go on its own journey" (a service manager). Although participatory structures varied from full community control to less formal community health forums, significant factors in all cases were community ownership, local knowledge, relationship-building, careful planning and the development of trust.

\section{Service requirements}

Although environmental enablers set essential parameters at the macro level, other micro-level requirements must be in place for the PHC model to be successful.

\section{Governance, management and leadership}

Effective governance, management and leadership were consistently identified as priorities for successful implementation of models, especially the NWQAHS, KWHB, RARMS and MTHCS models. Moreover, a strong PHC approach, encompassing community participation, multidisciplinary practice, a focus on disease prevention, and a shared leadership vision for the service, characterised these models.

Service "champions" at both the community and political levels were also important. A senior bureaucrat referred to the need for three types of key players: "visionaries" (leaders), "implementers" (managers) and "political runners" (experienced and committed officers who could pre-empt or overcome political barriers to implementation).

Governing committees or community boards contributed significantly to service sustainability. The leadership provided by key health professionals, themselves often community members, was also mentioned. This highlighted a dilemma for some small communities, where conflicts of interest can arise because a few key individuals perform multiple roles.

Service adaptability in a constantly changing environment required key managers capable of effective change management, so that services could take advantage of emerging opportunities and enhance sustainability. This was exemplified in several services, which adapted to chronic disease management through strategies that included better use of MBS items and information technology (IT), embracing a multidisciplinary 
approach, and ensuring adequate physical infrastructure to facilitate non-clinical interaction with patients. High-quality service evaluation also assisted with change and service improvement.

Localised management was also perceived as important. For example, NWQAHS adopted an explicit "place management" model that emphasised devolved management. Conversely, in services without strong local management or devolved authority, where management from a distance was not effective, or governance and management functions were not adequately distinguished, effectiveness and sustainability were threatened.

\section{Funding}

Adequate funding and appropriate funding mechanisms are prerequisites for establishing sustainable services. In one case, the "cashing out" of on-call payments for hospital visiting medical officers provided a more financially attractive package for GPs. In another service, adoption of a multidisciplinary approach to chronic disease management optimised income through greater access to relevant MBS items.

Despite the improved flexibility to respond to community needs associated with pooling and cashing out of funds, financing barriers still exist. A bureaucrat noted that although funds pooling was "a nice policy, it was difficult to implement". Another highlighted the need to streamline funding and rationalise the number of programs. In contrast, a third senior bureaucrat perceived the plethora of federal and state funding programs as providing opportunities for entrepreneurs to "tap dance" between programs in order to aggregate sufficient funding to meet community needs.

Both service providers ("success breeds success") and senior bureaucrats ("success binds public servants and politicians to the outcomes") agreed that reputation and credibility enhance a service's ability to attract funds. Ironically, although this success increased funds from multiple sources and enhanced sustainability, it also resulted in substantially increased reporting to multiple programs.

\section{Linkages}

The establishment of linkages with other organisations was also important in implementation and sustainability. Effective working relationships between organisations and their leaders facilitate access to a broader range of services, professional development activities, peer support, and credentialling for new recruits. Most services had strong links with organisations such as the Australian Government Department of Health and Ageing, University Departments of Rural Health, the Royal Flying Doctor Service, rural workforce agencies, Divisions of General Practice, local government and regional health services. Alternatively, insufficient linkages, tensions with state health authorities, and inappropriate referral practices threatened service sustainability.

\section{Infrastructure}

Adequate infrastructure was vital for implementation and sustainability. For example, for the NWQAHS hub and spoke model, the relationship with Queensland Health was important as the service utilised the latter's infrastructure on site, with its own infrastructure at the hub. Efficient IT systems and appropriate physical infrastructure were particularly critical to effective chronic disease management.

\section{Workforce supply}

Workforce supply was not a dominant factor affecting implementation. In several services, managers were able to attract staff by conveying a sense of excitement about the model, participation in an innovative development, and the professional challenges and opportunities.

However, workforce supply was identified as a threat to sustainability and generalisability. To minimise the threat, managers paid particular attention to recruitment and retention. A rigorous staff selection process ensured committed and appropriately skilled staff were appointed. Teamwork, role delineation and staff autonomy were also important, as was spouse employment and satisfaction.

Investment in staff maintenance was highlighted and included strategies such as:

- funding of professional development activities;

- housing and child care allowance;

- fares for periodic visits to place of initial recruitment;

- mentoring;

- career planning and pathways for advancement;

- flexibility of employment with respect to location and staff rotation; and

- flexibility to accommodate recreational and professional development needs.

\section{DISCUSSION}

This study has confirmed critical environmental enablers and essential service requirements that underpin effective $\mathrm{PHC}$ service models in rural and remote areas. This evidence-based PHC models framework has proved to be a robust and useful tool in the development of these services. ${ }^{6,9,10}$ Moreover, effective PHC services were shown to systematically address all essential service requirements across a range of models, from discrete general practices to Aboriginal community-controlled comprehensive PHC services.

Currently in Australia, there are several significant policy reviews relating to primary health care, disease prevention and the broader health system. Internationally, there is renewed interest in PHC. ${ }^{19}$ Our study provides important evidence from exemplary PHC models that can inform policy development. As the case-study design may limit generalisability of the results, there is a need for rigorous, comparative studies based on this evidence that evaluate the effectiveness of different service models using both qualitative and quantitative methods. ${ }^{20}$

Good governance, visionary leadership and high-quality management skills are crucial attributes of effective services. PHC services require stronger recognition of managers as essential members of the PHC team, and appropriate management and governance training.

Genuine community involvement is fundamental to the initiation and sustainability of rural and remote PHC services, although the mechanism for participation will vary across different contexts and services. Given its importance, explicit funding and appropriate time are required to support community consultation and ongoing participation in planning and development.

At the same time, communities must be realistic about the range of services that can be expected. Catchment or community size is critical, as the population needs to be sufficiently large to support an appropriate range of services, but not so large that dedicated specialist or disease-specific programs would usually be provided.

Sustained political commitment is crucial to successful PHC reform. Changing political priorities remain a barrier to developing widespread, effective PHC services across rural and remote Australia. Each PHC service benefited from the existence of distinct, relevant "mainstream" or rural "equalisation" policies, with the exception of one that relied on pre-election activism in a key 
swinging seat before a national election. Policies abound when rural health is perceived to be a political problem, but ad-hoc and some equalisation policies may be at risk when there is no perceived problem. Over time, incumbent governments may eschew risks associated with generalising successful models into different contexts, instead favouring "innovative pilots", which invariably have limited longevity. At the same time, federal-state relations remain complex and fraught, typified by fear of cost-shifting, with Commonwealth funding used to overcome state underservicing. Even positive strategies to overcome this divide, such as funds pooling, are difficult to implement.

Strong, visionary political leadership is needed to achieve a more coordinated approach to health service delivery, characterised by enhanced governance, management and community involvement. A national rural and remote health policy and plan is required to guide the ongoing development of health services. At a time when national health care reform is a priority, the establishment of a single Australian health system, operationalised at a regional level, would obviate much of the inefficiency and poor coordination that currently characterise health care in rural and remote areas, and contribute to eliminating existing health status differentials between cities and the bush.

\section{ACKNOWLEDGEMENTS}

We are grateful to the Australian Primary Health Care Research Institute for its support of this study, and to the members of our reference group: Professor Ray Pong (Centre for Rural and Northern Health Research, Canada), Professor Martha Macleod (University of Northern British Columbia, Canada), Kim Snowball (Department of Health, Western Australia), Alma Quick (Office of Rural Health, Australian Government Department of Health and Ageing [DoHA]), Gordon Gregory (National Rural Health Alliance), Dr lan Cameron (New South Wales Rural Doctors Network) and Mark Thomann (Office for Aboriginal and Torres Strait Islander Health, DoHA).

The Centre for Remote Health is funded by the DoHA University Department of Rural Health Program. Pim Kuipers holds an Australian Government Primary Health Care Research Evaluation and Development Fellowship.

\section{COMPETING INTERESTS}

None identified.

\section{AUTHOR DETAILS}

John Wakerman, MTH, FAFPHM, FACRRM, Director ${ }^{1}$

John S Humphreys, BA, DipEd, PhD, Professor of Rural Health Research ${ }^{2}$

Robert Wells, BA, Director, ${ }^{3}$ and Executive Director $^{4}$

Pim Kuipers, BA(Hons), MHumServ, PhD, Primary Health Care Research Evaluation and Development Senior Research Fellow ${ }^{1}$

Judith A Jones, BA(Hons),

GradDipAppSc(Comp), MSPD, Research

Fellow ${ }^{2}$

Philip Entwistle, PhD, Senior Research Fellow ${ }^{1}$ Leigh Kinsman, BHSc, MHSc, Senior Research Fellow ${ }^{2}$

1 Centre for Remote Health, Flinders University and Charles Darwin University, Alice Springs, NT.

2 School of Rural Health, Monash University, Bendigo, VIC.

3 Menzies Centre for Health Policy, Australian

National University, Canberra, ACT.

4 College of Medicine and Health Sciences,

Australian National University, Canberra, ACT.

Correspondence:

john.wakerman@flinders.edu.au

\section{REFERENCES}

1 Australian Institute of Health and Welfare. Rural, regional and remote health: indicators of health status and determinants of health. Canberra: AlHW, 2008. (AlHW Cat. No. PHE 97; Rural Health Series No. 9.)

2 Wakerman J, Humphreys J. Rural and remote health - definitions, policy and priorities. In: Liaw S, Kilpatrick S, editors. A textbook of Australian rural health. Canberra: Australian Rural Health Education Network, 2008.

3 Hart JT. The inverse care law. Lancet 1971; 1: 405-412.

4 Humphreys JS. Translating rural health policy into effective practice: barriers and solutions. In: McSwan D, McShane M, editors. Proceedings of the International Conference on Issues Affecting Rural Communities; 1994 Jul 10-15; Townsville, Old.

5 Humphreys JS, Wakerman J, Wells R. What do we mean by sustainable rural health services? Implications for rural health research. Aust $J$ Rural Health 2006; 14: 33-35.

6 Wakerman J, Humphreys JS, Wells R, et al. Primary health care delivery models in rural and remote Australia: a systematic review. BMC Health Serv Res 2008; 8: 276.

7 Shannon C, Wakerman J, Hill P, et al. Achievements in Aboriginal and Torres Strait Islander
Health. Darwin: Cooperative Research Centre for Aboriginal and Tropical Health, 2003.

8 World Health Organization. Declaration of Alma-Ata. International Conference on Primary Health Care, Alma Ata USSR, 6-12 September 1978. Geneva: WHO, 1978.

9 Wakerman J, Humphreys J, Wells R, et al. A systematic review of primary health care delivery models in rural and remote Australia 19932006. Canberra: Australian Primary Health Care Research Institute, 2006. http://www.anu. edu.au/aphcri/Domain/RuralRemote/Final_25_ Wakerman.pdf (accessed Mar 2009).

10 Humphreys JS, Wakerman J, Wells R, et al. "Beyond workforce": a systemic solution for health service provision in small rural and remote communities. Med J Aust 2007; 188 (8 Suppl): S77-S80.

11 Stanley-Davies P, Battye K. The Division with the vision: development of the North West Queensland Allied Health Service by North and West Queensland Primary Health Care. Evaluation of Stage 1. Townsville, Qld: NWOPHC, 2004.

12 Cromwell D, Senior K, Owen A, et al. Can the National Palliative Care Strategy be translated into a model of care that works for rural Australia? An answer from the Griffith Area Palliative Care Service (GAPS) experience. Wollongong, NSW: Centre for Health Service Development, University of Wollongong, 2003.

13 Local Evaluation Team. Jirntangku Miyrta Katherine West Coordinated Care Trial final report. Darwin: Menzies School of Health Research, 2000.

14 Cameron I. Finding solutions in north west NSW: "easy entry, gracious exit" and the Rural and Remote Medical Services (RARMS) experience. In: Practice made perfect? Conference proceedings and outcomes. NSW Rural Doctors Network; Coffs Harbour, NSW; 23-24 Feb 2005: 8-12. http://www.nswrdn.com.au/client_ images/246234.pdf (accessed Jun 2009).

15 Snowball K. Multipurpose services - a potential solution for rural health and aged care. Aust J Rural Health 1994; 2: 37-40.

16 Campbell A. The evaluation of a model of primary mental health care in rural Tasmania. Aust J Rural Health 2005; 13: 142-148.

17 Green J. The use of focus groups in research into health. In: Saks M, Allsop J, editors. Researching health: qualitative, quantitative and mixed methods. London: Sage, 2007.

18 Liamputtong P, Ezzy D. Qualitative research methods. Melbourne: Oxford University Press, 2005.

19 World Health Organization. The world health report 2008. Primary health care - now more than ever. Geneva: WHO, 2008.

20 Wakerman J. Innovative rural and remote primary health care models: what do we know and what are the research priorities? Aust J Rural Health 2009; 17: 21-26.

(Received 24 Apr 2009, accepted 1 Jun 2009) 